\title{
Innovation Capability, Knowledge Management and Big Data Technology: A Maritime Business Case
}

\author{
http://dx.doi.org/10.3991/ijac.v9i2.6010 \\ Maria A. Lambrou \\ University of the Aegean, Chios, Greece
}

\begin{abstract}
We present an updated knowledge management approach to foster companies' proficiency to formulate and implement their innovation strategies for new business models, services and markets, interlinked with knowledge management and learning technology resources and capabilities, in today's highly uncertain environment. We elaborate the generic framework, also in view of a maritime business case.
\end{abstract}

Index Terms-big data technology, innovation capability, knowledge management, maritime

\section{INTRODUCTION}

We aim at explaining a model of systematic innovation management, which is based on strategic management theory, in specific the management of dynamic capabilities (DC) in conjunction with knowledge management and emergent big data technology.

The systematic innovation capability of companies constitutes a higher order construct that is manifested as a configuration of business activities leading to continuous, sustainable business model innovation, product/service, or process and market-level innovation. Based on the presented theoretical framework, we link innovation orientation and capabilities of companies with their knowledge management capability and emergent technology, in particular, big data technology. We contribute to the development and formalization of a more extensive/updated knowledge management approach, adopted in distinct stages of the innovation process, towards further strengthening companies' proficiency to formulate and implement their strategies for new business models, services and markets, interlinked with knowledge management and learning technology resources and capabilities, in today's highly uncertain environment. We formulate the generic framework via a specific test example of the maritime sector applications.

We refer to innovation as "the transformation of business models, products/services, operations and processes, and organizational methods that enable performance benefits for companies, their customers and supply chain collaborators, as interrelated with changes in the macro environment and enabled by emergent technology" [1], [2].

Different innovation modes exist, with companies focusing either on incremental improvements or radical changes, also planned vs. emergent or ad-hoc vs. systematic innovation projects. A sector specific perspective is also important; the prevailing service sector innovation patterns are quite different from those in the manufactur- ing sector, or the public sector ones. The main drivers of innovation range from seeking competitive advantage with cost-leadership or differentiation, to continuous improvement and business excellence orientation. Henceforth, knowledge management practices and systems are correspondingly approached to support the overall innovation orientation of companies. Such knowledge management efforts and approaches also vary as regards their formality, intensity and technological sophistication.

Reference [3] discussed innovation activities from the perspective of process management, and divided the innovation processes within companies into five stages. Namely, (i) the processing of signals in the macro environment, (ii) formulation of strategies, (iii) procurement of resources, (iv) implementation, and (v) learning and reinnovation. Thus, knowledge management and absorptive capacity are typically considered of paramount importance for companies' innovation activities.

Successful companies, across sectors, longitudinally employ e-business platforms and practices to both optimize their business operations but also better coordinate and enable knowledge management as a fundamental source of competitive strategic (innovation) advantage, within the firm but also through their function and close ties with their value chain and innovation ecosystem(s) collaborators. Henceforth, a wealth of data historically aggregated and a corporate information infrastructure available for smooth information technology upgrades is the mainstream business case, nowadays. As the emergent forms of digital technology, namely Internet of Things (IoT) technology and Big Data Analytics (BDA) technology constitutes the latest forceful digital technology trajectory, research efforts are increasingly focusing on the consequences on firm strategy and operations, including knowledge management processes, and henceforth the associated innovation affordances [4], [5], [6], [7]. Datification as an emerging reality for strategy and operations management paves the way to new forms of serviceorientation for both manufacturing and service sectors, with ramifications and consequences for their mere transformation into knowledge-intensive settings. For instance, robotics and autonomous systems technology may well transform the shipping work environment on board (vessel/fleet level), also new forms of artificial intelligence (i.e. big data technology) bear plausible changes for the strategy making, decision-making and (technical/commercial) operations management; nevertheless both human/managerial cognition and advanced business software tools will be operant and co-evolving into the 
near future, with pertinent ramifications for the knowledge and human capital management realms and their enabling technology systems.

\section{INNOVATION CAPABILITY}

DCs are a construct of the resource-based view (RBV) of strategic management. DCs are defined as the "ability to integrate, build, and reconfigure internal and external competences to address rapidly changing environments" [8], [9]. DC is divided into the following components: (i) the capacity to sense and shape opportunities and threats; (ii) the capacity to seize opportunities; and (ii) the capacity to maintain competitiveness. We center our analysis on the systematic innovation capability (a derivative construct of DCs); systematic innovation capability is a higher order construct composed of reinforcing practices and processes within the firm and manifested in observable and also not immediately observable configurations of resources and capabilities, and harder to depict causality relationships of these enacted elements. These processes are a fundamental mechanism for stimulating, measuring and reinforcing innovation. The elements making up an innovation capability can be grouped into a number of major elements, including innovation strategy, innovation resourcing, structures and culture, organizational intelligence, technology management, and innovation performance management. In the following we present those innovation capability components with strong correlation to knowledge management, namely; strategy, organizational intelligence and culture, so as to closer examine the role of emergent knowledge management technology in firms' innovation orientation and capability.

\section{A. Strategy and Governance}

Innovation theory emphasizes the link between vision, strategy and innovation as important to effective innovation management. Strategy determines the configuration of resources, products, processes and systems that firms adopt to deal with the uncertainty existing in their environment, also the decisions about markets to enter or continue operating in.

Innovation in companies is associated with a wellfounded, insightful expression of the firm's strategic direction, as enabled by associated leadership styles and governance forms.

A new mode of operation for strategy making and decision-making is gradually emerging, where decision makers' and strategists' experience and intuition is complemented with data-driven routines and practices, commonly understood as knowledge-rich practices. Digitization and datification's power does not obliterate the need for strategic vision and human cognition. Data-driven management and governance are observed to have an increasing, positive impact on innovation performance [10], [11].

\section{B. Learning Orientation and Organizational Intelligence}

Organizational intelligence has been defined as "the capability to process, interpret, encode, manipulate and access information in a purposeful, goal-directed manner, so it can increase the firm's adaptive potential in the environment in which it operates" [12]. Since knowledge and ideas are primary inputs into the innovation process, intelligent firms can use this information to identify new avenues for investigation and to more quickly eliminate unprofitable options. Reference [13] shows that high- performing innovators proactively used environment scanning, technological forecasting and competitive analysis toward this goal. A strong appetite for continuous learning from customers and about competitors along with privileged access to professional knowledge sources and actors of the innovation cluster, i.e. financial and market intelligence institutions is considered to enable high performing companies to successfully innovate by timely entering new, lucrative markets and/or developing new services. Datification has a dramatic influence on the scope/variety, velocity, quality and differential value of organizational intelligence capability for innovation orientation and performance.

The process of generating, learning and applying knowledge about competitors' products/services, processes and strategies or emergent business models is also critical. Competitor learning plays two significant roles: position diagnostic benchmarking and position advantage [12]. A firm with superior competitor information can use this knowledge to apply its strengths against a rival's weakness, internalize competitors' strengths by imitation and improvement or discount the strength. Thus, we postulate that successful companies exhibit a conscious, positive learning orientation concerning their customers and business partners in their value chain, and also their competitors, through a range of organizational intelligence mechanisms. The latter are dramatically transformed by the emerging datification of the overall business and societal fabric.

\section{Culture and Climate}

The appropriate culture and climate within the organization is also vitally important to innovation success. The components commonly identified as underlying the innovation boosting culture and climate are; tolerance of ambiguity and failure, risk-taking mentality, empowered employees, favorable conditions for creativity and idea management, and communication [3]. This is not necessarily explicitly linked to a conscious innovation-oriented strategy, but often to a competitive human resource management strategy.

Creativity may be viewed as the process of generating ideas that are formally channeled though the innovation funnel, within a company. Successful companies typically expect or "allow" creativity, in terms of divergent thinking, by senior management, also knowledge and white collar employees, within limits. Successful companies may foster various forms (formal, non-formal) of communication as a conscious approach to foster performance improvements and innovation.

The emergent datification has a multifaceted impact on companies' innovation culture; the advanced digitization of operations and decision-making processes fosters the transformation into a data-enabled and knowledge oriented organizational culture, thus accelerating the possibilities for empowerment and (talent) development of people in the company, across industries. Hence, firms, across industries, gradually develop into service and knowledge intensive ones with associated structures, norms and culture, enabled by the prevalence of digitization and datification. 


\section{Co-EXAMINING KNOWLEDGE MANAGEMENT AND INNOVATION}

Knowledge management and innovation as a combined theme is an under investigated area. Extant research has identified three main orientations of knowledge management approaches, practices and systems. The classification is dependent on whether information technology, a human resources or the organizational culture orientation drives knowledge management. An information technology orientation views technology as the enabler for knowledge management capability. A human capital orientation takes a more socio-cognitive, behavioral focus, whereas an organizational culture approach takes a resource based view where knowledge is regarded as a strategic resource. These three basic orientations are manifested in specific sectoral, and organizational contexts and henceforth generate diverse knowledge management priorities, methods and system configurations.

Reference [14] presents a thorough review of extant research on knowledge management and innovation; firstly, the relationship between knowledge management and levels of innovation, also with levels of competitiveness in organizations is discussed and the strategic nature of knowledge development is exemplified. Knowledge management positively influences innovation and competitiveness. Innovation involves the mobilization of knowledge, and successful knowledge management approaches for innovation have common factors; knowledge management is commonly leveraged as a coordinating mechanism to enhance both innovation and organizational performance; also the development of modern human resource management methods like talent management to support knowledge management and innovation.

Reference [14] recently validated empirically the impact of sound knowledge management practices across a number of the building blocks of innovation. The authors find that the areas where knowledge management strongly supports innovation include (a) strategy and leadership, also (b) human resource management, (c) organizational learning, and (d) organizational culture.

Since, the potential of knowledge management to influence innovation and achieve competitive advantage increases significantly with effective knowledge management approaches and systems, big data technology is considered to significantly redefine knowledge management systems' value, in the near future.

\section{KNOWledge Management ANd Big DatA}

As quite broadly discussed by academics and professionals, "big data technologies denote a new generation of technologies and architectures, designed to economically extract value from very large volumes of a wide variety of data, by enabling the high-velocity capture, discovery, and/or analysis" [15]. Hence, the well-known big data attributes are regularly denoted as Volume (great volume), Variety (various modalities), Velocity (rapid generation), and Value (great value); certainly the value creation from Veracious (of appropriate quality) big data computing and application being the most relevant and interesting issue today, including value for new knowledge management oriented applications/services that support systematic innovation management in companies.

Many of the commercial or emergent big data applications are interrelated with operational and/or transactional data, offering new forms of knowledge about business operations, supply chains, or distribution channel performance or on customer/consumer behavior (business intelligence). Big data technology, in particular, has the potential to add value by "providing transparency with immediate performance feedback, experimentation with quick results, more precise segmentation, more objective decision-making (algorithms rather than humans), and associated new products/service design"[16]. Big data and business analytics bring new capabilities, with an apparent need though for clear and insightful directions for future research on the possible intersections with knowledge management, in particular, competitive intelligence, business intelligence and intellectual capital elements. Leading IT companies, including Oracle, IBM, Microsoft, Google, or Facebook have already developed big data projects, while today the focus is also on big companies and SMEs, across every sector, examining the feasibility, maturity and business value of big data project(s), tailored to their particular sector regularities and firm strategies. To the best of our knowledge, there is not yet a critical research community formed to pave the way by selectively working on platforms/products for knowledge management in the era of big data support; rather it is assumed that knowledge will be pervasively embedded in big data enabled enterprise systems for decision-making or operational support, henceforth necessary adjustment for knowledge management creation and exploitation, as such, is not clearly/explicitly pondered in academia or the IT industry yet [17], [18].

It is postulated that a revamped, knowledge management centered design philosophy should be devised in the era of natively, knowledge oriented, big data enterprise platforms, in a fashion that perceptibly and deliberately enable and guide systematic innovation management activities, throughout a company's structure and along its innovation ecosystem(s).

\section{The MARITIME Business CASE}

Hereafter, we focus on a combined scheme for big data enabled knowledge management systems, in support of maritime innovation capability [19].

The main areas along which big data driven knowledge management initiatives can be addressed in maritime organizations are the following:

\section{A. Strategy and decision making in shipping companies}

Strategy making in shipping is primarily about investment appraisal and portfolio management, including elements of ship valuations and asset play, risk assessment for financing options, along with market (tanker, drilling, liner, bulk etc.) scanning and positioning or exit determination. The immediately foreseeable possibility for new information services enabled by the near-time collection of a variety of big data sources, public/open and private/corporate for interpreting and predicting markets evolution and companies preferred strategic adjustment is considered the closest knowledge management systems evolution approach in todays' big data design mindset.

In shipping, utmost research and development emphasis has been concentrated in, primarily IoT based, (a) ship health monitoring (predictive maintenance) applications, (b) energy consumption/efficiency monitoring (d) emissions/environmental impact monitoring platforms also (e) 
safety and security platforms for critical incidents / piracy monitoring.

Both commercial software for shipping companies (i.e. WAVES by DANAOS platform for vessel/fleet performance monitoring) and centralized policy oriented for operational authorities support (i.e. https://bluehub.jrc.ec.europa.eu, with vessel tracking and trade routes analysis functionality) are currently emergent.

\section{B. Competitive intelligence: knowing yours shippers, suppliers and competitors}

The objective of maritime competitive intelligence primarily refers to collecting and analyzing available data resources to identify patterns of collaborators', customers' and competitors' business behavior patterns. Predictive competitor behavior (i.e. liner shipping companies serving the same trade routes), deciphers the strategies underpinning the observable actions, and enables the anticipation of future strategic and tactical moves. Likewise the future behavior of customers (shippers, forwarders, charterers) i.e. long-term shippers, liner shippers etc. can be more confidently analyzed and support decision-making. The above directions constitute an unexplored area of knowledge management for the maritime domain and a major immediate driver for maritime big data and business intelligence technology and applications development. Related technology ranges from social media based sentiment analysis (inferring users' opinions) for trade/market/freight rates prediction, to integrated, applications for market/commercial trends prediction.

\section{Human capital development: on board and ashore}

Maritime human capital development needs are assessed to necessitate a major re-orientation as regards both hard and soft skills (www.know-me.org), where "current maritime industry needs and future trends should be complemented by modern maritime education and training concepts". New challenges for seafarers, such as working with high-tech equipment on board, working as part of a nearly unmanned, mega ship, poses new technical requirements for a more skilled workforce. Future seafarers will need to be "technically literate and be equipped with problem-solving, decision-making and communication skills". White-collar maritime professional are also seen to be continuously challenged by new knowledge and training/education access and certification requirements. Current trends in e-learning and knowledge management, as advanced by big data technology are anticipated to be also soon infused in the maritime education and training sector; i.e. development of skills estimation and course recommendation products as interrelated with maritime market needs and trends, or improved maritime e-learning platforms with advanced learning analytics.

\section{Data-driven culture: from craftsmanship to knowledge and science orientation}

The maritime industry is undergoing (another) major paradigm shift, nowadays. A new technological trajectory is currently evolving with smart ships, smart ports and logistics infrastructures constituting and equivalent of Industry 4.0 for the maritime domain. Big data technology is a major component for both the vessel and the shipping company node, where all seafarers, maritime scientists and professionals at the offices are increasingly performing their work tasks in a data based and technology de- pendent manner. An innovation-orientated mentality is also gradually gaining momentum in the shipping environment, whereas the development of new strategies for timely entering profitable markets (geographic or other), also developing new services and processes, are redesigned in light of big data enabled decision-support and operational support maritime software. Seen from a system level viewpoint, knowledge management is currently considered to be, in essence, supported by the main functionalities of the enterprise (and policy) software available, thus enabling in an improved manner the systematic innovation capability of shipping companies. However, this has not been evaluated yet, as regards its effectiveness; we can postulate that unless appropriately designed, visualized and dialogued knowledge management-in the big data era- applications for systematic innovation support are developed and tested, knowledge management support for systematic innovation capability is happening as a side effect and hence forth in a suboptimal manner.

Critical matters remain (a) the cautious reconsideration of the cognitive models associated with knowledge management and decision making, in the big data enabled organizational paradigm, also (b) revisiting knowledge management as a highly human social process, in the context of the intensified digital network organizational paradigm [20].

\section{SUMMARY}

Data is considered nowadays an important business resource, comparable to material assets and intellectual capital. In most industries, companies seeking sustainable operation increasingly, deliberately manage innovation orientation and systematic innovation capabilities. In this context, the knowledge management theory and tools are at a new formative stage, where the very nature of the knowledge creation, management and sharing process is redefined, in light of a heightened innovation orientation corporate mindset. In the present position paper, we presented a conceptual, combined analysis of the above themes, namely big data enabled knowledge management, fostering systematic innovation capability. An example maritime business case is presented in order to highlight pertinent application areas and design and management issues.

\section{ACKNOWLEDGMENT}

The presented work is inspired and based on my broader research work on Innovation Management in Shipping, as developed with a sabbatical academic visit to the University of Melbourne, kindly hosted and generously, academically supported by Professor Daniel Samson.

\section{REFERENCES}

[1] J. Bessant, Innovation and manufacturing strategy, in The Handbook of Industrial Innovation, eds. M. Dodgson \& R. Rothwell (Cheltenham: Edward Elgar), 1994.

[2] H. W. Chesbrough, H. W. (2010) "Business Model Innovation: Opportunities and Barriers”, Long Range Planning, Vol. 43, 2010, pp. 354-363. http://dx.doi.org/10.1016/j.lrp.2009.07.010

[3] J. Tidd, J. Bessant, and K. Pavitt, Managing Innovation: Integrating Technological, Market and Organizational Change, Wiley, New York, 2001.

[4] M. A. Akaka and S. L. Vargo "Technology as an operant resource in service (eco)systems", Information Systems and E-Business Management , Vol. 12 No. 3, 2014, pp. 367-384. http://dx.doi.org/10.1007/s10257-013-0220-5 
PAPER

Innovation CAPABility, Knowledge Management And Big Data TeChNOlogy: A Maritime Business Case

[5] R. F. Babiceanu and R. Seker, "Big Data and virtualization for manufacturing cyber-physical systems: A survey of the current status and future outlook", Computers in Industry, 2016, in press. http://dx.doi.org/10.1016/j.compind.2016.02.004

[6] E. Brynjolfsson and A. McAfee, A. The Second Machine Age: Work, Progress, and Prosperity in a Time of Brilliant Technologies, W.W. Norton, New York, NY, 2014.

[7] A. McAfee and E. Brynjolfsson, "Big data: the management revolution”, Harvard Business Review, Vol. 90 No 10, 2012, pp. 60-68.

[8] D. J. Teece, G. Pisano, G. and A. "Dynamic capabilities and strategic management", Strategic Management Journal, Vol. 18, No 7, 1997, pp. 509-533. http://dx.doi.org/10.1002/(SICI)10970266(199708)18:7<509::AID-SMJ882>3.0.CO;2-Z

[9] D. J. Teece, "Explicating dynamic capabilities: the nature and microfoundations of (sustainable) enterprise performance", Strategic Management Journal, Vol. 28, No 13, 2007, pp. 1319-1350. http://dx.doi.org/10.1002/smj.640

[10] R. Coombs, Technology and business strategy, in The Handbook of Industrial Innovation, eds. M. Dodgson \& R. Rothwell, Edward Elgar, 1994.

[11] A. Gawer and M. A. Cusumano, M. A., "Industry Platforms and Ecosystem Innovation”, Journal of Product Innovation Management, Vol. 31, 2014, pp.417-433. http://dx.doi.org/10.1111/ jpim. 12105

[12] M. A. Glynn, "Innovative genius: A framework for relating individual and organisational intelligences to innovation", Academy of Management Review, Vol. 21 No 4, 1996, pp. 1081-1111.

[13] S. D. Saleh and C. K. Wang, "The management of innovation: Strategy, structure and organisational climate", IEEE Transactions on Engineering Management, Vol. 40 No 1, 1993, pp. 14-21. http://dx.doi.org/10.1109/17.206645

[14] M. Gloet and D. Samson, "Knowledge Management to Support Systematic Innovation Capability", in Proceedings HICSS, 2013,
2014 47th Hawaii International Conference on System Sciences, 2013, pp. 3685-3694 http://dx.doi.org/10.1109/hicss.2013.374

[15] M. Chen, S. Mao, and Y. Liu "Big data: A survey" Mobile Networks and Applications, Vol. 19, No.2, 2014, pp. 171-209. http://dx.doi.org/10.1007/s11036-013-0489-0

[16] J. Manyika, et al., "Big data: the next frontier for innovation, competition, and productivity", McKinsey Global Institute, 2011.

[17] S. Erickson and H. Rothberg, "Big Data and Knowledge Management: Establishing a Conceptual Foundation", Electronic Journal of Knowledge Management, Vol.12, No 2, 2014

[18] K. Verbert, N. Manouselis, H. Drachsler and E. Duval, "Datasetdriven research to support learning and knowledge analytics", Journal of Educational Technology \& Society, Vol. 15, No. 3, 2012, pp. 133-148.

[19] D. Samson, M. Ota, M. A. Lambrou, "Systematic Innovation Capabilities in Shipping: Validation of an established Innovation Process Model", in Proceeding of ICSI, 2014 5th International Conference on Systematic Innovation, San Jose, CA USA.

[20] L. Uden, M. Hericko, I. Ting, Knowledge Management in Organizations, eds. Lecture Notes in Business Information Processing (LNBIP 224), Springer, 2015.

\section{AUTHOR}

Maria A. Lambrou is an Associate Professor of eBusiness with the University of the Aegean, Business School, Department of Shipping, Trade and Transport, Greece (e-mail: mlambrou@ aegean.gr).

This article is an extended and modified version of a paper presented at the the International Conference on E-learning in the Workplace 2016 (ICELW 2016), held in June 2016, at Columbia University in New York, NY, USA. Submitted 11 April 2016. Published as resubmitted by the author 26 May 2016. 